\title{
Menghapus citra buruk njai dalam karya-karya fiksi berbahasa Melayu (1896-1927)
}

\author{
MAYA SUTEDJA-LIEM
}

\begin{abstract}
In the Dutch colonial literature of the mid nineteenth century, the njai (Asian concubine) is the symbol of degeneration and of undermining colonial society in the Dutch Indies. Opposed to this portrayal, in Malay literature the image of the njai is on the whole positive: she is faithful and loyal to her partner, intelligent, and economical. However, she easily falls victim to external powers, which is often the masculine power of the society she belongs to. In many Malay texts she is represented as ready to fight back, primarily for the sake of the future of her offspring(s) or herself. Sometimes she succumbs, sometimes she triumphs. Examples can be found in texts like Tjerita Njai Dasima (1896), Tjerita Nji Paina (1900), Seitang Koening (1906), Hikajat Raden Adjeng Badaroesmi (1901-1903), Tjerita Njai Isah (1904), and Boenga roos dari Tjikembang (1927). These texts represent a re-evaluation of the njai and stand in opposition to nineteenth century Dutch colonial literature.
\end{abstract}

KEYWORDS

Sastra Melayu (Malay literature), njai (concubine), citra (image), kesetiaan (faithfulness), perlawanan (opposition).

Njai adalah julukan bagi seorang wanita pribumi, kadangkala juga bagi seorang wanita Cina, yang hidup bersama pria Eropa, Cina atau Arab tanpa hubungan pernikahan. Walaupun tidak mempunyai kedudukan resmi sebagai ibu rumahtangga, seorang njai umumnya memegang peran ibu rumah tangga di rumah sang pria. Sudah di zaman VOC (Vereenigde Oost-Indische Compagnie) atau Persekutuan Dagang Hindia-Timur sejumlah lelaki hidup bersama dengan seorang njai tanpa pernah menikahinya secara resmi, pun jika sang njai telah melahirkan anak dari lelaki itu.

MAYA SUTEDJA-LIEM adalah lulusan Department of Languages and Cultures of Southeast Asia and Oceania, Leiden University, Belanda; menyelesaikan disertasinya berjudul The turning wheel of time; Modernity and writing identity in Bali 1900-1970 tahun 2003 pada universitas yang sama. Sejak tahun 1995 bekerja sebagai penerjemah novel berbahasa Melayu dan Indonesia ke dalam bahasa Belanda; karya terjemahan terakhir berjudul: De Njai; Moeder van alle volken; De roos van Tjikembang en andere verhalen (2008; Leiden: KITLV Uitgeverij). E-mail: mayahtliem@gmail.com. 
Di zaman VOC, sejak tahun 1652 hanya para petinggi dan pedagang VOC terpenting yang diperbolehkan datang ke Hindia-Belanda bersama isteri (Taylor 1986: 14-15). Sebelum diadakannya peraturan pembatasan tersebut, VOC justru melancarkan kedatangan para wanita dari Belanda. Selain isteri para petinggi VOC, juga kelompok-kelompok kecil gadis Belanda didatangkan ke Hindia-Belanda untuk menetap dan menikah dengan pejabat-pejabat VOC berpangkat tinggi maupun rendah. Hal ini merupakan suatu kebijakan pemerintah VOC untuk mengurangi kecenderungan pada para pria Belanda hidup bersama seorang njai, yang pada saat itu dianggap tidak sesuai dengan peradaban tinggi orang Belanda. Namun, mulai sekitar tahun 1647 terdengar suara-suara yang tidak menghendaki kedatangan wanita dari Belanda, dengan pemberian dalil, bahwa wanita Belanda meningkatkan pengeluaran pemerintah. Di samping itu, dikatakan juga bahwa dengan dorongan para isteri, pejabat-pejabat VOC lebih mementingkan dirinya dan cenderung membuka perdagangan pribadi dengan merugikan VOC. Akhirnya pada tahun 1652 ditetapkan bahwa hanya isteri para petinggi dan pedagang VOC tertinggi diizinkan datang ke Hindia-Belanda.

Di kalangan pegawai perkebunan Belanda/Eropa sampai tahun 1922 masih berlaku larangan untuk menikah dengan wanita Eropa (Lucas 1986: 82). Peraturan tersebut berdasarkan perhitungan bahwa pegawai muda dan bujangan memerlukan gaji yang lebih rendah daripada seorang pegawai yang berkeluarga. Di samping itu, diperkirakan juga bahwa sebuah pernikahan dengan wanita Eropa dapat menghambat hubungan antara pegawai perkebunan dan penduduk pribumi.

Maka dengan sendirinya jalinan hubungan antara pria Eropa dan wanitawanita pribumi tetap berlangsung. Sejumlah besar pria Belanda dan wanita pribumi hidup dalam pernikahan resmi. Namun, pernyaian, di mana wanita pribumi menempati kedudukan sebagai pengurus rumah tangga sekaligus sebagai pengganti isteri sang laki-laki yang juga 'majikannya', tetap umum dan bahkan dikehendaki oleh para pengusaha perkebunan bagi pegawaipegawai muda mereka.

Jika seorang laki-laki akhirnya memutuskan menikah dengan seorang wanita Eropa, misalnya dengan dalil bahwa pernikahan resmi dengan wanita Eropa lebih menguntungkan bagi karier laki-laki itu, maka hal ini sering kali membawa nasib buruk bagi si njai: wanita yang telah hidup sekian lama sebagai pendamping laki-laki Eropa ini dan merupakan ibu dari anaknya, harus meninggalkan rumah tangganya, misalnya dengan hanya sekedar membawa uang sebagai pengganti rugi. Anaknya pun seringkali harus diserahkan kepada yang laki-laki.

Namun, banyak juga pria yang tetap memilih hidup tanpa pernikahan resmi dengan seorang njai dan tidak menikahi seorang wanita dari negaranya sendiri. Alasannya, secara keuangan seorang njai tidak banyak memberi beban, sebab terbiasa hidup sederhana, sedangkan wanita Eropa terbiasa dengan tingkat kehidupan yang tinggi. 


\section{CITRA NJAI DALAM SASTRA}

Di abad kesembilan belas hidup dengan seorang njai merupakan kebiasaan yang sudah dapat diterima oleh masyarakat Hindia-Belanda. Walau demikian, citra seorang njai pada umumnya negatif. Dalam sastra kolonial Hindia-Belanda njai, yang ditampilkan berulang-ulang, sering digambarkan sebagai wanita yang tidak setia, yang mengincar harta sang pria, dan yang suka balas dendam terhadap 'majikannya' dengan menggunakan gunaguna, sehingga terbentuk sebuah gambaran stereotipe yang negatif dari njai. Dapat dikatakan sastra kolonial Hindia-Belanda memupuk citra negatif para njai. Termorshuizen (1996 dan 2000) tidak mendapatkan gambaran njai yang positif dalam sastra kolonial Hindia-Belanda, kecuali dalam dua karya, yakni dalam sajak A.M. Voorneman Sjia, De kampongroos (Sjia, Mawar Kampung) (1887) dan novel P.A. Daum Aboe Bakar (1894). Henk Maier (1990: 165-173) berpendapat bahwa njai dalam sastra kolonial, misalnya dalam novel P.A. Daum Nummer Elf (Nomor Sebelas) (1981), memenuhi kebutuhan masyarakat kolonial untuk mempertajam perbedaan (ras) antara orang berkulit putih dan penduduk setempat. Dalam novel tersebut njai dipergunakan sebagai lambang degenerasi, lambang peruntuhan masyarakat kolonial. Citra yang serba buruk ini mempengaruhi penerimaan para njai oleh masyarakat luas. Kehidupan serta jati diri seorang njai yang sesungguhnya jarang dapat diketahui, bahkan merupakan tabu bagi sanak-saudara wanita itu sendiri.

Berbeda halnya dengan sastra kolonial Hindia-Belanda yang tertulis dalam bahasa Belanda, dalam mayoritas karya fiksi berbahasa Melayu dari akhir abad kesembilan belas dan awal abad kedua puluh terdapat gambaran yang menunjukkan simpati terhadap para njai. Pada umumnya seorang njai digambarkan mempunyai kedudukan sosial yang sangat lemah, karena ia tidak terlindungi oleh hak-hak yang dimiliki oleh wanita yang menikah secara resmi, meskipun secara ekonomis seorang njai lebih beruntung daripada wanita-wanita pribumi lainnya. Ia tidak dapat berbuat apa-apa jika akan ditinggalkan seorang diri, ketika laki-lakinya mencapai kedudukan penting dalam masyarakat dan memilih menikahi seorang wanita berkulit putih. Acapkali si njai tidak berhak memiliki anaknya sendiri, sehingga ibu dan anak akan terpisah untuk selama-lamanya. Dengan demikian, dapat dikatakan bahwa njai yang muncul dalam karya-karya fiksi berbahasa Melayu umumnya adalah njai yang baik dan yang selalu menjadi korban para pria, apakah itu penjajah Belanda, para priyayi Jawa atau pedagang Cina. Singkatnya, njai menjadi korban dari kekuasaan maskulin yang kejam.

Di antara sejumlah besar karya fiksi, enam buah yang terbit antara 1896 dan 1927 dan yang terjemahan bahasa Belandanya termuat dalam buku De njai; Moeder van alle volken; De roos van Tjikembang en andere verhalen (2008), menunjukkan bahwa karya-karya modern yang ditulis dalam bahasa Melayu merupakan cerminan upaya untuk mengubah citra njai yang buruk menjadi citra yang menggugah simpati dan menambah pengertian. Enam karya tersebut masing-masing adalah Tjerita Njai Dasima (1896), karya Gijsbert Francis; Nji Paina (1900), karya Herman Kommer; Seitang Koening (1902), 
karya Raden Mas Tirto Adhi Soerjo; Hikajat Raden Adjeng Badaroesmi (19011903), karya Johannus Everadus Tehupeiory; Tjerita Njai Isah (1901/1904), karya Ferdinand Wiggers; dan Boenga Roos dari Tjikembang (1927), karya Kwee Tek Hoay. Seorang njai umumnya digambarkan sebagai setia pada prianya, bersedia untuk bekerja keras dan sangat hemat. Nampaknya, keenam karya tersebut mencerminkan perubahan mentalitas di Hindia-Belanda yang bertujuan menghapus citra buruk masyarakat pribumi dan membentuk sebuah gambaran baru yang lebih manusiawi.

Segenap pengarang karya-karya tersebut di atas, yakni Francis, Kommer, Tirto Adhi Suryo, Tehupeiory, Wiggers, dan Kwee Tek Hoay, menjabat sebagai pemimpin redaksi dan jurnalis surat-surat kabar Melayu ternama, seperti Pembrita Betawi, Bendera Wolanda, Soerat Chabar Soldadoe, dan Medan Prijaji. Mereka masing-masing menginginkan agar Hindia-Belanda berkembang menjadi dunia modern di mana media cetak merupakan suatu sarana terpenting untuk dapat membicarakan dan memperdebatkan masalah-masalah kemasyarakatan dan politik, menyarankan suatu solusi, mengungkapkan kritik atau membentuk opini umum. Sastra merupakan sebuah medium yang sangat berguna untuk mencapai tujuan ini, karena dengannya para pengarang tidak hanya dapat menawarkan hiburan kepada para pembaca, namun sekaligus menemukan sarana untuk menyalurkan pandangan pribadi masing-masing pengarang dalam bentuk fiksi - hal yang biasanya sulit mereka lakukan melalui tulisan-tulisan yang memuat berita atau dalam sebuah tajuk. Maka karya-karya fiksi seperti yang disebut di atas dapat ditafsirkan sebagai 'suara-suara' pribadi dalam wacana yang melibatkan masa depan Hindia-Belanda. Di dalamnya njai melambangkan negara yang terjajah dan rakyat yang tertindas. Namun, di samping itu juga dia merupakan penghubung antara berbagai ras dan bangsa. Darinya lahir anak dari berbagai macam bangsa: Eropa, Cina, Arab, dan Indonesia; njai adalah ibu semua bangsa. Maka posisi, peran, dan masa depannya tidak dapat diabaikan begitu saja, bahkan memerlukan perhatian khusus.

\section{MENGANGKAT HARKAT: KESETIAAN SEORANG NJAI}

Dari keenam cerita, karya Francis Tjerita Njai Dasima merupakan satusatunya yang pada pandangan pertama belum meninggalkan pencitraan $n j a i$ yang negatif, sebagaimana umum terdapat dalam sastra kolonial HindiaBelanda. Dalam Cerita Njai Dasima ketidaksetiaan pada lelaki dan anak masih mencorengi citra Njai Dasima, tokoh cerita ini. Njai Dasima meninggalkan lelakinya, orang Inggris, dan anak perempuannya, walaupun sangat cinta pada mereka. Namun, kesan buruk dari diri Njai Dasima yang terbentuk oleh perbuatan tersebut segera beralih menjadi kesan yang lebih memihak pada si njai, berdasarkan kasus penipuan di balik keputusan pergi ini: Njai Dasima menjadi korban tipu muslihat seorang laki-laki Muslim yang memakai gunaguna, agar si njai meninggalkan rumahnya dengan membawa sejumlah besar harta si lelaki, orang Inggris. Setelah sadar akan penipuan atas dirinya, Njai Dasima berupaya keras untuk membubarkan pernikahannya dengan laki-laki 
Muslim itu dan kembali ke kekasihnya yang orang Inggris serta anaknya. Namun, upaya itu ternyata sia-sia dan justru menyebabkan kematiannya. Dia dibunuh oleh si suami itu beserta para kawannya.

Pencitraan seorang njai sebagai korban penipuan, seperti dalam Tjerita Njai Dasima, sedikit mengubah citra stereotipe para njai yang umum di dalam sastra kolonial Hindia-Belanda. Ketidaksetiaan bukan lagi berdasarkan kepribadian buruk si njai - yang sebenarnya sangat setia, baik, tulus, dan jujur - tetapi adalah akibat dari kuasa dan kejahatan seseorang di luar dirinya (acapkali pelaku kejahatan adalah seorang pria). Di dalam fiksi berbahasa Melayu yang terbit setelah tahun 1900 gambaran njai sebagai korban kuasa dan kejahatan menjadi umum, seperti juga dibuktikan dalam cerita-cerita yang termuat dalam De njai; Moeder van alle volken; De roos van Tjikembang en andere verhalen (2008).

Dalam Tjerita Njai Isah, karya F. Wiggers, dan cerita Boenga Mawar dari Tjikembang, karya Kwee Tek Hoay, pencitraan njai sebagai korban tekanan eksternal ternyata sangat berguna untuk menggarisbawahi kesetiaan njai dan sekaligus mengangkat harkatnya. Dalam karya Wiggers, kesetiaan dikedepankan sebagai ciri khas terpenting dari kepribadian Njai Isah, tokoh utama cerita Njai Isah. Pertama kali hal itu tampil ke depan adalah pada waktu kekasih Njai Isah yang orang Belanda, Verkerk, kehilangan pekerjaannya di perkebunan kopi di Bagelen, akibat harga pasaran kopi yang melambung tinggi. Dalam keadaan yang serba sulit ini, Njai Isah tetap setia pada kekasihnya, dan tanpa diminta dia bersedia bekerja keras untuk menghidupi kekasih dan anaknya. Isah berkeliling dari desa ke desa dengan cikar untuk membeli padi, yang kemudian ditumbuknya sendiri menjadi beras dan menjualnya di pasar. Selain itu, dia keliling menjual ketan, pisang goreng, dan lain-lainnya (Wiggers 1904: 224-225). Karakterisasi Njai Isah sebagai wanita yang setia, rajin, dan penuh tanggung jawab ini, dimaksudkan untuk menggugah simpati para pembaca, seperti dapat dibaca melalui kata-kata tokoh-tokoh cerita lainnya yang memuja-muja. Seperti kata seorang controleur yang bersimpati pada Njai Isah:

Betoel, maka itoe djoega kita orang Blanda tida patoet aken namain njai-njai itoe orang tida baik, dan kaloe akoe fikirin betoel-betoel prihalnja Verkerk maka soenggoe terlebi beroentoeng bagi dia jang dia tida kawin. Tjobalah sandenja dia kawin njonja Blanda, abis dia dapet tjilaka begini, tjara sebagimana dia mesti idoep? Apa itoe njonja kawin sanggoep dan maoe naik pedati sampi pegi ka desa-desa berdagang? Apa itoe njonja maoe djoewalan pisang goreng, ketan dan laen-laen di djalan? Akoe rasa tida ada satoe jang maoe. (Wiggers 1904: 233-234).

Kedua kalinya kesetiaan Njai Isah diketengahkan dalam sebuah fragmen yang sangat mengesankan. Dalam fragmen tersebut Njai Isah bersama Verkerk pergi menonton pertunjukan Komedi Stambul yang memainkan cerita Njai Dasima. Njai Isah mengikuti permainan di atas panggung dengan hati terpesona, sampai pada adegan di mana Njai Dasima meninggalkan anaknya. Hatinya trenyuh melihat adegan tersebut. Njai Isah segera pergi, tanpa 
menunggu sampai pertunjukan berakhir. Kepada Verkerk dia mengutarakan keberangannya mengenai citra njai yang tercipta dalam Tjerita Njai Dasima:

Sampe di sini, si Isah tida maoe tinggal lama-an menonton itoe lakon, ia adjakin Verkerk poelang, maka Verkerk heran kenapa Isah maoe poelang dengen paksa, sebab dalem atinja Verkerk, lakon ini betoel bagoes sekali, itoe waktoe Dasima ambil selamat tinggal dari toewannja dan anaknja, ia itoelah paling bagoes [...] 'Toewan, saja tida bisa liat satoe perampoewan jang begitoe tida ada tjinta barang sedikit di dalem hatinja.' 'Tjinta apa?' 'Tjinta pada toewannja jang begitoe baik padanja, dan paling-paling, ia itoe tjinta pada anak kandoengannja sendiri. Dasima terlebi tjinta dia poenja igama jang begitoe lama dia sia-siaken. Toewan, itoe barang moestail, soedah, saja bisa trima, jang orang perampoewan kaloe soenggoe tjinta igamanja, dia bisa meloepa-in tjinta pada soewaminja [...]. [..] tetapi jang ia bisa berpisah dari pada anak jang dikandoengnja sendiri, dari pada darah dagingnja sendiri itoe barang jang tida bole djadi. Tjinta satoe emak pada anaknja ia itoelah tjinta jang paling besar di doenia [...]. (Wiggers 1904: 213-214).

Fragmen tersebut merupakan serangan terbuka terhadap Tjerita Njai Dasima dan karya-karya fiksi lainnya yang meragukan kesetiaan seorang njai. Kesetiaan njai kepada kekasihnya, dan terutama kepada anaknya, tidak dapat diganggu gugat. Hal ini dibuktikan oleh Njai Isah sendiri, ketika dia tertipu muslihat seorang wanita berkulit putih, Poppie, yang adalah adik ipar majikan Verkerk. Ketika Poppie membujuk Verkerk dengan memakai guna-guna, agar dia meninggalkan Njai Isah dan membawa anaknya pergi dari ibunya, Njai Isah rela ditinggalkan oleh Verkerk, tetapi tidak rela dipisahkan dari anaknya. Dia membawa anaknya terjun ke dalam sungai di belakang rumah mereka. Dengan demikian, Njai Isah menepati janji yang diucapkannya pada waktu pertunjukan Tjerita Njai Dasima, walaupun dia dan anaknya akhirnya diselamatkan juga oleh penduduk lain desa. Seumur hidupnya dia tetap setia pada anaknya.

Kesetiaan njai juga jelas menempati kedudukan utama dalam cerita Boenga roos dari Tjikembang, karya Kwee Tek Hoay. Marsiti, njai tercinta dari seorang pria Tionghoa, Ay Tjeng, post-mortem tetap setia pada kekasih dan anaknya. Marsiti adalah seorang njai yang atas paksaan orang tua lelakinya harus menyingkir dan memberi kesempatan kepada lelakinya untuk menikah dengan seorang wanita pilihan orang tua lelaki. Dengan sangat sedih Marsiti meninggalkan kekasihnya tanpa memberitahukan keberangkatannya dan tempat tinggal barunya. Sebelum pergi dia berjanji pada dirinya akan selalu setia pada Ay Tjeng, apapun yang terjadi. Ay Tjeng, yang tidak dapat menerima kepergian Marsiti, akhirnya belajar mencintai isterinya yang baru, karena ada kemiripan yang mencolok antara isterinya dan Marsiti. Sebelum ayah mertua Ay Tjeng meninggal, Ay Tjeng diberitahu olehnya sebuah rahasia besar yang menyangkut diri Marsiti, yaitu bahwa Marsiti adalah anak ayah mertuanya sendiri dengan seorang njai pribumi. Dengan kata lain, Marsiti adalah kakak tiri isteri Ay Tjeng. Ini yang menyebabkan kemiripan antara Marsiti dan isteri Ay Tjeng. Dengan sedih hati dan sangat menyesal ayah mertua Ay Tjeng mengabarkan juga bahwa Marsiti telah meninggal dunia 
akibat perpisahan dengan kekasihnya. Hal yang tidak sempat dikatakannya, sebelum menghembuskan nafas terakhir, adalah bahwa Marsiti mengandung anak Ay Tjeng, ketika meninggalkan rumah Ay Tjeng. Beberapa tahun ayah dan anak hidup terpisah, tetapi pada akhirnya Ay Tjeng menemukan anaknya atas bantuan roh Marsiti. Marsiti telah menepati janji: post-mortem dia tetap setia pada Ay Tjeng dan memberinya anak sebagai pengganti dirinya.

Ketiga karya fiksi di atas menunjukkan bagaimana kesetiaan njai kepada kekasihnya teruji berat oleh faktor-faktor yang berada di luar diri njai. Dalam ketiga cerita, si njai tidak berdaya memerangi kejahatan dan ketidakadilan yang akhirnya memisahkannya dari kekasihnya. Walaupun tanpa kesadaran penuh atau dengan sangat berat hati, akhirnya si njai rela meninggalkan kekasihnya. Lain halnya jika dia dipaksakan meninggalkan anaknya. Ketiga cerita memberikan solusi yang berbeda. Jika Njai Dasima dalam Tjerita Njai Dasima tidak menitikkan air mata sedikitpun, bahkan mendorong anaknya agar melepasnya dan tetap tinggal dengan ayahnya yang orang Inggris, maka Njai Isah dalam Tjerita Njai Isah mengerahkan segala tenaga untuk mempertahankan anaknya. Njai Isah memilih mengakhiri hidupnya bersama anaknya daripada menyerahkannya kepada lelakinya yang orang Belanda. Dia menginginkan agar anaknya akan besar sesuai dengan cita-citanya sendiri, yaitu hidup di pedalaman sebagai anak yang sederhana tetapi berpendidikan ${ }^{1}$. Marsiti dalam Boenga roos dari Tjikembang memilih hidup di akhirat di mana dia lebih berdaya menjaga keselamatan anaknya. Dia mendayaupayakan agar anaknya mendapat pengakuan penuh dan cinta dari ayahnya, yang memberinya pendidikan modern sebagai bekal untuk hidup lebih bahagia daripada dirinya.

Perhatian pada anak seorang njai menunjukkan adanya kesadaran akan nasib anak yang lahir dari hubungan pernyaian. Siapa yang berhak memiliki si anak jika pernyaian berakhir dengan perceraian? Bagaimana masa depannya jika dia ikut hidup dengan ayahnya atau ibunya? Pertanyaan-pertanyaan yang dapat diartikan secara harafiah, tetapi juga dapat ditafsirkan mengandung arti simbolis dan mengarah pada masa depan masyarakat Indonesia di bawah pemerintahan Hindia-Belanda dan setelahnya. Dalam cerita-cerita tersebut, solusi yang diberikan dapat dibaca sebagai 'suara' masing-masing pengarang dalam perdebatan mengenai masa depan Indonesia. Francis, pada bagian penutupan Tjerita Njai Dasima, menggambarkan nasib Njai Dasima berakhir dengan kematian, karena si njai gagal mempertahankan kesetiaannya pada

Dalam Tjerita Njai Isah halaman 442-443, di mana Verkerk dan Njai Isah memperdebatkan masa depan putra mereka, Wimpie, Njai Isah mengatakan ia menginginkan Wimpie menjadi seorang petani saja. Tidak perlu pendidikan: 'Moestail manoesia tjoema bisa beroentoeng dengan peladjaran dan sekola jang baik dan pangkat besar? Tiadakah toewan kira, jang orang tani bisa beroentoeng? Saja rasa orang tani terlebi beroentoeng di dalem doenia dari pada orang-orang laen. Sebab dia hasil kringat lelahnja dengan boekti. Tiadakah dia nanti beroentoeng, kaloe dia liat sawahnja bertoemboe bagoes dan padinja gemoek?'. Tetapi pada akhirnya Wimpie disekolahkan di sekolah Belanda di Djawa oleh seorang controleur Indo-Belanda bernama Laanhof, yang sebenarnya ingin mengambil Njai Isah menjadi njainya. Karena Isah masih mencintai Verkerk, dia hanya menginginkan agar Laanhof memberi Wimpie pendidikan yang baik. Lihat Wiggers 1904: 233. 
keluarganya dan memilih hidup dengan seorang pribumi beragama Islam yang bersifat jahat. Masa depan anaknya yang lahir dari hubungan pernyaian dengan orang Inggris, dengan sendirinya menjadi tanggung jawab ayahnya, jika kesetiaan ibu tidak dapat diandalkan.

Wiggers, dalam Tjerita Njai Isah, menampilkan seorang njai yang tidak rela menyerahkan anaknya pada tanggung jawab ayahnya yang orang Belanda. Kesetiaannya sebagai seorang ibu menjadi jaminan pertama untuk menanggung masa depan anaknya. Dia bercita-cita membesarkan anaknya di pedalaman dan menjadikannya seorang pribumi sederhana yang berpendidikan.

Kwee Tek Hoay, dalam Boenga roos dari Tjikembang, menggambarkan nasib buruk seorang njai dan masa depan yang lebih cerah bagi anaknya. Berbeda dari penghujung cerita dalam karya Wiggers, karya Kwee berakhir dengan menaruh tanggung jawab anak pada ayahnya, orang Tionghoa, seperti yang dikehendaki oleh ibunya sendiri. Kesetiaan seorang ibu terhadap suami dan anak perempuannya menjadikan anak perempuannya itu dapat bersatu kembali dengan ayahnya dan dengan begitu masa depan yang disongsong anaknya itu juga lebih terjamin daripada masa depannya sendiri.

Maka dapat dikatakan, dari ketiga cerita tersebut, karya Wiggers paling mencerminkan kepercayaan penuh pada masa depan yang berada di bawah tanggung jawab seorang 'ibu' dan seorang pribumi.

\section{DARI POSISI TERTINDAS MEMERANGI KETIDAKADILAN}

Selain njai yang setia, gambaran yang sering tampil ke depan adalah gambaran njai yang berani dan cerdik. Dalam posisi tertindas atau sebagai korban kejahatan dan ketidakadilan, dia melakukan perlawanan untuk menyelamatkan diri atau mereka yang dia cintai. Citra njai yang terbentuk akibatnya adalah njai sebagai wanita yang tegas dan siap berjuang. Dia tidak selalu berhasil, bahkan kadang-kadang menebus perlawanannya dengan nyawanya. Tjerita Njai Dasima memberikan contoh seorang njai yang gagal menyelamatkan diri dari tipu muslihat seorang laki-laki dan kekuatan gunaguna dengan segala dampaknya.

Juga Hikajat Raden Adjeng Badaroesmi (1901-1903), karya Tehupeiory, memperlihatkan seorang wanita yang gagal: Nji Pia menderita sakit jiwa, karena tersingkirkan oleh kekasihnya Raden Mas Ario Sosro Deksono. Akhirnya dia bunuh diri setelah membalas dendam dengan membunuh menantu laki-lakinya.

Berbeda dari kedua karya di atas, tiga cerita, yakni Tjerita Nji Paina ${ }^{2}$ (1900), karya Kommer; Seitang Koening (1906), karya Tirto Adhi Soeryo; dan Tjerita Njai Isah, karya Wiggers, menampilkan njai sebagai tokoh wanita yang berjaya. Contoh yang paling mengesankan adalah Nji Paina. Kommer merupakan pengarang pertama yang menciptakan fenomena baru dalam sastra Melayu: seorang wanita yang berkuasa atas kehidupannya sendiri.

\footnotetext{
2 Judul yang lengkap: Tjerita Nji Paina; Satoe anak gadis jang amat satia; Satoe tjerita amat indahnja, jang belon sebrapa lama soedah terdjadi di Djawa Wetan. Batavia: Veit.
} 
Dia berperan sebagai lambang kemenangan dan kebebasan. Nji Paina, putri seorang pegawai pabrik gula bernama Niti Atmodjo, terpuruk ketika ayahnya memaksanya menikah dengan seorang atasan Prancis bernama Briot. Briot sudah lama mempunyai hasrat dan mengincar Nji Paina. Karena sadar bahwa Nji Paina tidak menghendakinya, Briot memojokkan Niti Atmodjo dengan mengajukan tuduhan terhadapnya telah mencuri uang pabrik gula. Pembayaran kembali hanya dapat dilaksanakan dengan pemberian putrinya sebagai isteri Briot. Karena tidak ingin mempersulit ayahnya, Nji Paina berpura-pura mau. Tetapi sebelum bertemu dengan Briot, dia menularkan diri dengan penyakit cacar. Baru kemudian dia memperisterikan diri kepada Briot, yang tidak lama setelahnya tertular penyakit cacar dan meninggal dunia. Nji Paina sendiri selamat dan hidup berbahagia selama-lamanya.

Citra yang terbentuk dalam cerita ini bukanlah njai sebagai wanita yang baik atau sebaliknya jahat, seperti umum didapatkan dalam cerita yang mengisahkan riwayat hidup njai, namun seorang wanita yang cerdik dan berani memerangi ketidakadilan yang menimpa keluarganya dan dirinya. Dia berjuang untuk melepaskan diri dari ketergantungan pada seorang jahat dan memakai kecerdikannya untuk membalas dendam dengan mengakhiri hidup musuhnya. Dalam sebuah artikel Maier (1990:172) berpendapat, bahwa Kommer tidak menampilkan tokoh njai untuk menunjukkan adanya pertentangan rasial, namun pertama-tama untuk menyadarkan para pembaca akan ketidakadilan sosial di sekitarnya, dan kedua untuk membebaskannya dari ketergantungan yang termasuk 'sindrom Caliban'. ${ }^{3}$

Dengan terciptanya tokoh seorang njai yang simpatik (baik, setia, dan sering menjadi korban kejahatan), siap berjuang, dan bebas, maka sejarah sastra Melayu memasuki babak baru. Boleh dikatakan citra njai yang baru ini menandai lahirnya karya fiksi modern dalam bahasa Melayu.

\section{DAFTAR PUSTAKA}

Francis, G. 1896. Tjerita Njai Dasima; Soewatoe korban dari pada pemboedjoek tjerita bagoes sekali jang belon berapa lama soedah djadi di Betawi; Akan mendjadi peladjaran bagei sekalian prempoean jang soeka menoeroet boedjoekan laki-laki. Batavia.

Kommer, H.(F.R.) 1900. Tjerita Nji Paina; Satoe anak gadis jang amat satia; Satoe tjerita amat Indahnja, jang belon sebrapa lama soedah terdjadi di Djawa Wetan. Batavia: Veit.

Kwee, Tek Hoay. 1927. Boenga roos dari Tjikembang. Batavia: Panorama.

Lucas, N. 1986. "Trouwverbod, inlandse huishoudsters en Europese vrouwen; Het concubinaat in de planterswereld aan Sumatra's Oostkust 1860-1940". di dalam: Jeske Reijs et al. (red.), Vrouwen in de Nederlandse koloniën; Zevende jaarboek voor vrouwengeschiedenis, hlm. 78-97. Nijmegen: SUN.

3 Maier (1990: 172) menggunakan kata-kata berikut: '[...] Kommer used the figure of Njai less to describe the racial problems in the colony (no matter how urgent they were) than to draw the reader's attention to class conflicts. [...] Here, casualness and recognizeability are pushed to as yet unexplored borders: a strong attempt indeed to shake off the Caliban-syndrom of dependency'. 
Maier, H.M.J. 1990. "Some genealogical remarks on the emergence of modern Malay literature", Journal of the Japan-Netherlands Institute 2: 159-177. (Papers of the Dutch-Japanese Symposium on the History of Dutch and Japanese Expansion, In Memory of the Late Nagazumi Akira, Tokyo and Kyoto, 9-14 October 1989).

Soerjo, Raden Mas Tirto Adhi. 1906. “Seitang Koening”, Doenia-pertjintaan; 101 tjerita jang soenggoe soedah terdjadi di Tanah Priangan. Makassar: Brouwer \& Co.

Sutedja-Liem, M. 2008. De njai; Moeder van alle volken; De roos van Tjikembang en andere verhalen. Leiden: KITLV Uitgeverij.

Taylor, Jean Gelman, 1986. "Europese en Euroaziatische vrouwen in Nederlands-Indië in de VOC-tijd", di dalam: Jeske Reijs et al. (red.), Vrouwen in de Nederlandse koloniën; Zevende jaarboek voor vrouwengeschiedenis, hlm. 10-33. Nijmegen: SUN.

Tehupeiory, J.E. 1901-1903. "Hikajat Raden Adjeng Badaroesmi", Bendera Wolanda, 22 oktober 1901 - 18 mei 1903.

Termorshuizen, Gerard. 1996. “Vrouwen spreken tegen; Mondige nyai's in romans van Pramoedya Ananta Toer en P.A. Daum", di dalam: Theo D'haen (red.), Weer-werk; Schrijven en terugschrijven in koloniale en postkoloniale literaturen, hlm. 31-44. Leiden: Vakgroep Talen en Culturen van ZuidoostAzië en Oceanië, Rijksuniversiteit te Leiden. (Semaian 15).

Termorshuizen, Gerard. 2000. "Het Indische literaire feuilleton in de koloniale pers", Indische Letteren 15: 204-211.

Wiggers, F. 1904. Tjerita Njai Isah. Djilid 1. Batavia: NV tot Exploitatie van Mal. week- en andere bladen in Ned. Indië. 